\title{
Midventricular Hypertrophic Obstructive Cardiomyopathy with Left Ventricular Aneurysm and Clot: The Role of Transesophageal Echocardiogram in Assessment and Management of Myomectomy
}

\author{
${ }^{1}$ Vikas Dutta, ${ }^{2}$ Ravi Raj, ${ }^{3}$ Bhupesh Kumar, ${ }^{4}$ Ajay Bahl, ${ }^{5}$ Shyam KS Thingam, ${ }^{6}$ Sunder Lal Negi, ${ }^{7}$ Goverdhan Dutt Puri
}

\begin{abstract}
Hypertrophic obstructive cardiomyopathy (HOCM) with mid ventricular obstruction leading to apical aneurysm and clot is very rare. Intraoperative transesophageal echocardiogram (TEE) can be used to know the maximum thickness of the septum, its distance from the aortic annulus and the apical extent of septal bulge. Postresection TEE can provide information about residual obstruction or any complications. We present a case of 65-year-old male patient who underwent CABG, septal myectomy, Dor's procedure for aneurysm and clot removal. Septal resection was done under TEE guidance.
\end{abstract}

Keywords: Hypertrophic cardiomyopathy, Midventricular obstruction, Transesophageal echocardiography.

How to cite this article: Dutta V, Raj R, Kumar B, Bahl A, Thingam SKS, Negi SL, Puri GD. Midventricular Hypertrophic Obstructive Cardiomyopathy with Left Ventricular Aneurysm and Clot: The Role of Transesophageal Echocardiogram in Assessment and Management of Myomectomy. J Perioper Echocardiogr 2014;2(2):58-60.

Source of support: Nil

Conflict of interest: None

\section{INTRODUCTION}

Hypertrophic obstructive cardiomyopathy (HOCM) is a genetic myocardial disorder characterized usually by asymmetric left and/or right ventricular hypertrophy. ${ }^{1}$ Ventricular septal hypertrophy is the most common type of asymmetric hypertrophy, while other types like

\footnotetext{
1,2,6 Senior Resident, ${ }^{3}$ Assistant Professor

${ }^{4}$ Associate Professor, ${ }^{5,7}$ Professor

1-3,6,7 Department of Anesthesia and Intensive Care, Postgraduate Institute of Medical Education and Research Chandigarh, India

${ }^{4}$ Department of Cardiology, Postgraduate Institute of Medical Education and Research, Chandigarh, India

${ }^{5}$ Department of Cardiothoracic and Vascular Surgery, Postgraduate Institute of Medical Education and Research Chandigarh, India

Corresponding Author: Goverdhan Dutt Puri, Professor Department of Anesthesia and Intensive Care, Postgraduate Institute of Medical Education and Research, Chandigarh India, Phone: 9914209509, e-mail: gdpuri007@hotmail.com
}

with midventricular and apical occurring much less frequently. ${ }^{2}$ Mid ventricular obstruction leading to apical aneurysm formation is seen in $2 \%$ of HOCM patients. ${ }^{3} \mathrm{We}$ present a case of HOCM with mid ventricular obstruction leading to apical aneurysm formation. The role of intraoperative transesophageal echocardiogram (TEE) in assessment and during myomectomy is also discussed.

\section{CASE REPORT}

65-year-old male, a known case of HOCM on treatment with amlodipine presented to our emergency department with history of upper gastrointestinal bleed following non-steroidal anti-inflammatory drugs (NSAIDS) ingestion for fracture clavicle, sustained 5 days back. He had stroke 3 years back with spontaneous recovery. His transthoracic echocardiogram (TTE) examination showed a mid cavity gradient of $48 \mathrm{~mm} \mathrm{Hg}$, apical aneurysm of left ventricle (LV) with a large clot in it and normal left ventricular systolic function. Coronary angiogram revealed $90 \%$ stenosis in left anterior descending artery, diagonal 1 and ramus. He was planned for coronary artery bypass grafting (CABG) plus myectomy and clot removal.

Intraoperative TEE showed mid interventricular septal (IVS) hypertrophy $(23.5 \mathrm{~mm})$ with apical aneurysm and a clot in LV apex (Fig. 1). The septal hypertrophy was not asymmetrical. The inferolateral wall was also thickened. Colour flow Doppler showed a turbulent flow in the mid LV cavity and continuous wave Doppler revealed peak gradient of $94 \mathrm{~mm} \mathrm{Hg}$. There was no associated mitral regurgitation, systolic anterior motion of anterior mitral leaflet or significant gradient across left ventricular outflow tract (LVOT). There were no associated abnormalities of papillary muscles or chordal insertion. The extent of myomectomy was assessed using TEE. In the mid esophageal aortic long axis view the distance of maximal septal thickness from the aortic annulus $(32.4 \mathrm{~mm})$, length $(31.9 \mathrm{~mm})$ and width $(23.5 \mathrm{~mm})$ of thickness were measured and informed to the surgeon (Fig. 2). Patient underwent CABG, IVS myectomy via transaortic approach, LV apical aneurysm repair (DOR procedure) and clot removal. Post repair, TEE showed the thinned out septum without any iatrogenic ventricular septal defect 


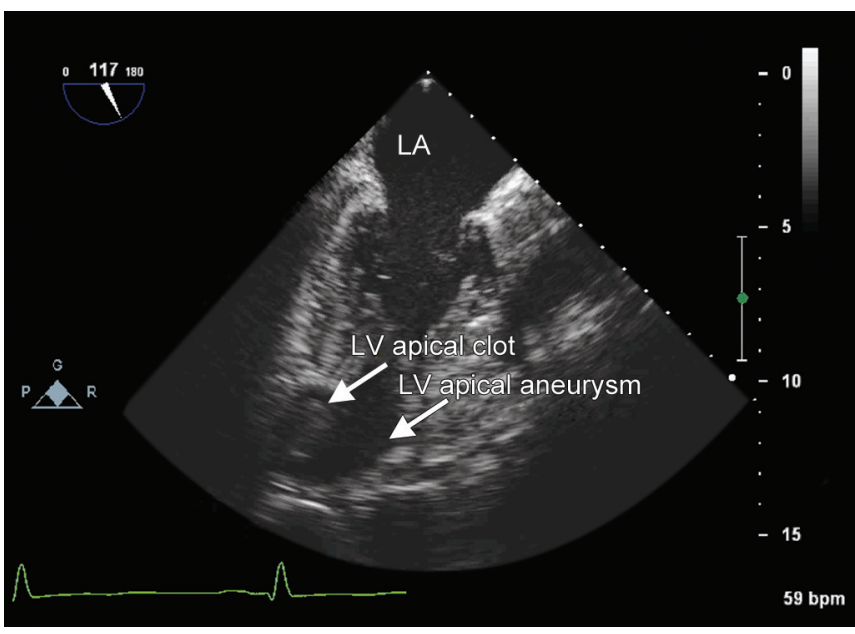

Fig. 1: Left ventricular apical aneurysm and clot

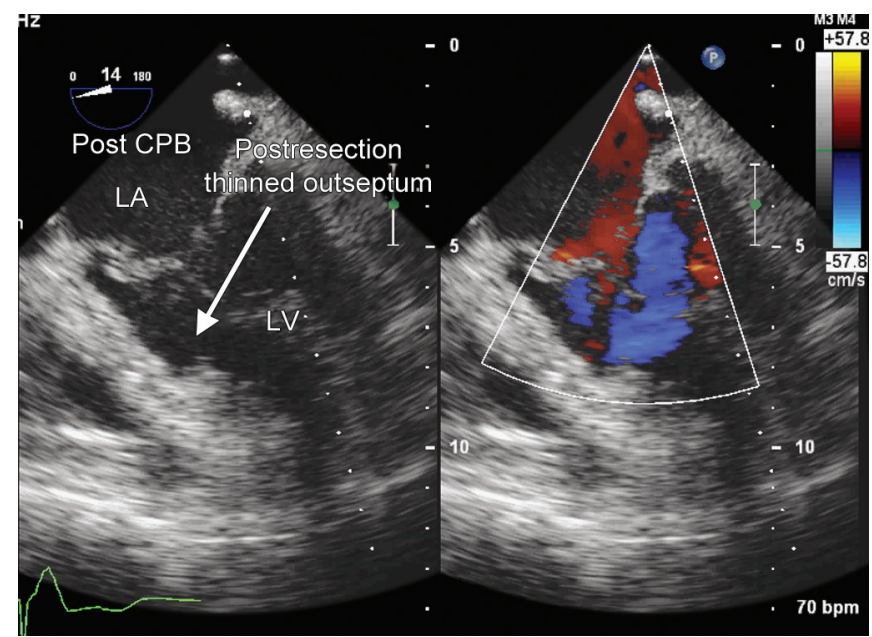

Fig. 3: Postresection thinned outseptum and no VSD

(Figs 3 and 4). The mid cavity gradient decreased to 25 $\mathrm{mm} \mathrm{Hg}$. There was no MR, AR or LVOT gradient. In the postoperative period patient developed complete heart block and was discharged with an automatic implantable cardioverter defibrillator (AICD).
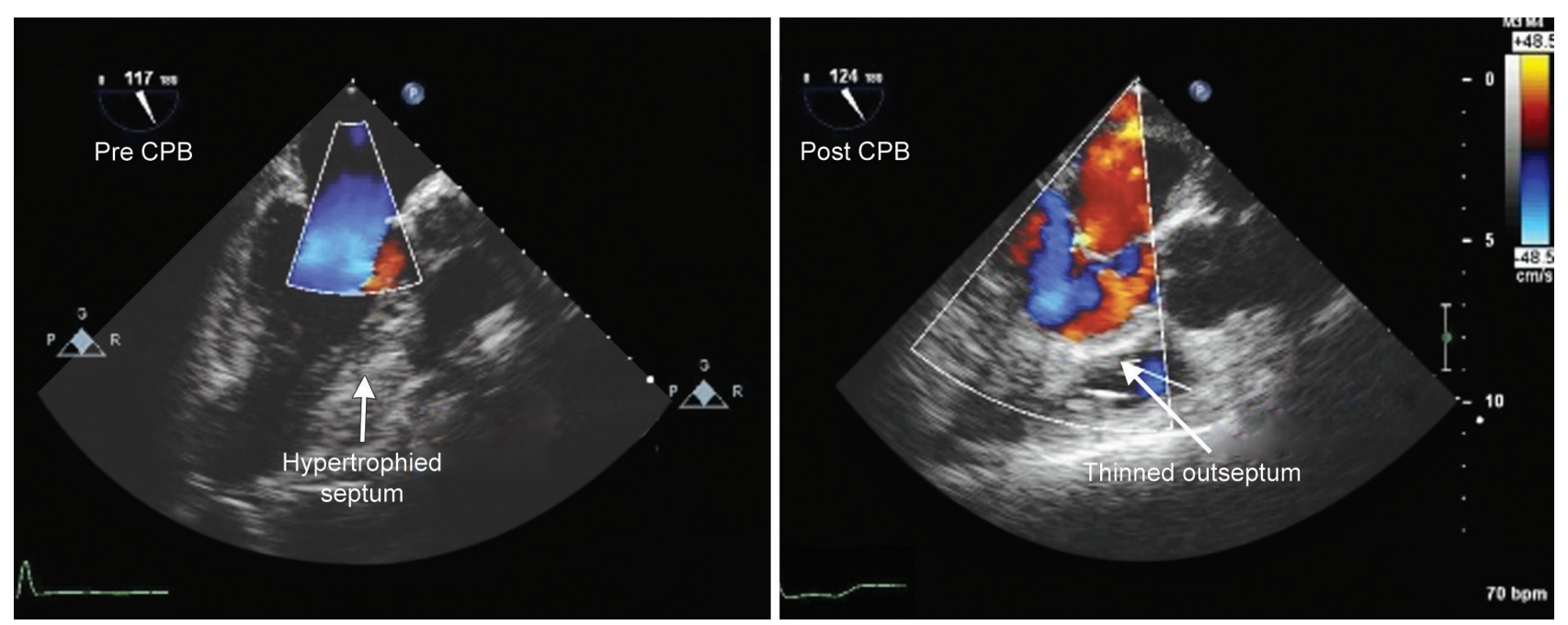

Fig. 4: Comparison of pre and post CPB interventricular septum in midesophageal long-axis view

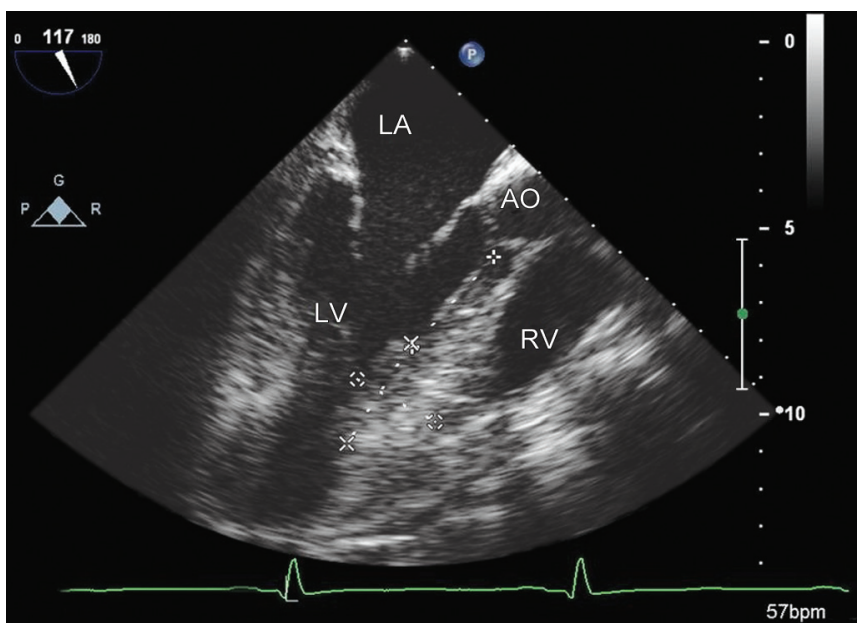

Fig. 2: Distance of myomectomy from the aortic annulus, depth of resection and extent of resection toward the apex is shown to the surgeon

\section{DISCUSSION}

Mid ventricular obstruction in HOCM is an independent determinant of potential lethal arrhythmia and sudden death. ${ }^{4}$ It is caused by hypertrophic septum coming in contact with a hypercontractile left ventricular free wall. ${ }^{5}$ Long period of exposure to mid ventricular obstruction and increased left ventricular wall stress may cause apical aneurysm formation. ${ }^{4}$ Midcavity obliteration to flow during systole might lead to compensatory apical hypertrophy, which by itself could make midventricular obstruction more severe. A stage is reached where the pressure overload in the apical chamber leads to myocardial dysfunction with dilation of the apical chamber. The dyskinetic/akinetic apical aneurysm can provide the structural basis for intracavitary thrombus formation. ${ }^{6}$ Other possible cause of LV aneurysm include post myocardial infarction. Our patient had no history of angina or myocardial infarction. There was no associated regional wall motion abnormality on ECHO although coronary angiogram suggested significant CAD. 
Surgical myomectomy in HOCM is recommended in patients refractory to medical management. Transesophageal echocardiogram is very useful during the procedure. It helps in planning the extent of the resection, assessing the immediate result and detecting any iatrogenic complications. 7,8 Transesophageal echocardiogram provides a road map of septal anatomy and geometry to the surgeon. Important information obtained from TEE includes the maximum thickness of the septum, the distance of maximum thickness from the aortic annulus, the location of the endocardial fibrous plaque (friction or impact lesion), and the apical extent of the septal bulge. ${ }^{9}$ In addition, some patients have very long redundant mitral valve leaflets where anterior mitral leaflet plication has been shown to limit systolic anterior motion (SAM). These functional or intrinsic mitral valve abnormalities are well characterized on TEE and can guide the necessary repairs or replacement. Iatrogenic aortic regurgitation due to direct injury to the leaflets or destabilization of the annulus due to myectomy too close to the right coronary cusp and iatrogenic ventricular septal defects, may be recognized easily on TEE, helping in adequate repair before coming off cardiopulmonary bypass. ${ }^{10}$ Transesophageal echocardiogram is also useful to assess the residual gradient and if the gradient is more than $50 \mathrm{~mm} \mathrm{Hg}$, revision myectomy should be considered..$^{11}$ In our case, post CPB TEE the gradient came down to $25 \mathrm{~mm} \mathrm{Hg}$.

\section{CONCLUSION}

Intraoperative TEE is an important tool in localizing site of gradient, planning the exact location and extent of myectomy, detecting adequacy of repair and diagnosing related iatrogenic complications.

\section{REFERENCES}

1. Braunwald E, Lambrew CT, Rockoff SD, Ross J Jr, Morrow AG. Idiopathic hypertrophic subaortic stenosis. I. A description of the disease based upon an analysis of 64 patients. Circulation 1964;29(5S4):IV3.

2. Wigle ED, Rakowski H, Kimball BP, Williams WG. Hypertrophic cardiomyopathy. Clinical spectrum and treatment. Circulation 1995;92(7):1680-1692.

3. Maron MS, Finley JJ, Bos JM, Hauser TH, Manning WJ, Haas TS, Lesser JR, Udelson JE, Ackerman MJ, Maron BJ. Prevalence, clinical significance, and natural history of left ventricular apical aneurysms in hypertrophic cardiomyopathy. Circulation 2008:118(15):1541-1549.

4. Minami Y, Kajimoto K, Terajima Y, Yashiro B, Okayama D, Haruki S, Nakajima T, Kawashiro N, Kawana M, Hagiwara N. Clinical implications of midventricular obstruction in patients with hypertrophic cardiomyopathy. JACC 2011;57(23): 2346-2355.

5. Falicov RE, Resnekov L. Midventricular obstruction in hypertrophic obstructive cardiomyopathy: new diagnostic and therapeutic challenge. Br Heart J 1977;39(7):701-705.

6. Fighali S, Krajcer Z, Edelman S, Leachman RD. Progression of hypertropic cardiomyopathy into a hypokinetic left ventricle: higher incidence in patients with mid ventricular obstruction. JACC 1987:9(2):288-294.

7. Grigg LE, Wigle E, Williams WG, Daniel LB, Rakowski H. Transesophageal Doppler echocardiography in obstructive hypertrophic cardiomyopathy: clarification of pathophysiology and importance in inraoperative decision making. JACC 1992;20(1):42-52.

8. Ommen SR, Park SH, Click RL, Freeman WK, Schaff HV, Tajik AJ. Impact of intraoperative transesophageal echocardiography in the surgical management of hypertrophic cardiomyopathy. Am J Cardiol 2002;90(9):1022-1024.

9. Nagueh SF, Bierig SM, Budoff JM, Desai M, Dilsizian V, Eidem B, Goldstein SA, Hung J, Maron MS, Ommen SR, et al. American Society of Echocardiography Clinical Recommendations for Multimodality Cardiovascular Imaging of Patients with Hypertrophic Cardiomyopathy. J Am Soc Echocardiogr 2011;24(5):473-498.

10. Smedira NG, Lytle BW, Lever HM, Rajeswaran J, Krishnaswamy G, Kaple RK, Dolney DO, Blackstone EH. Current effectiveness and risks of isolated septal myectomy for hypertrophic obstructive cardiomyopathy. Ann Thorac Surg 2008;85(1):127-133.

11. Marwick TH, Stewart WJ, Lever HM, Lytle BW, Rosenkranz ER, Duffy CI, et al. Benefits of intraoperative echocardiography in the surgical management of hypertrophic cardiomyopathy. J Am Coll Cardiol 1992;20(5):1066-1072. 